\title{
A MULTI-CRITERIA DECISION MAKING MODEL FOR CERAMIC TILES CONVEYOR SELECTION
}

\author{
Omayma A. Nada \\ Production Engineering and Mechanical Design Department, Faculty of Engineering, \\ Menoufia University, Shebin El-kom, Menoufia, Egypt.
}

\begin{abstract}
:
Material handling is one of the activities in manufacturing that can drastically affect not only the production cost but also the performance of the entire line, particularly in continuous and transfer manufacturing system. Therefore, selecting the most appropriate material handling equipment is a critical decision that should be could be carefully studied in the early stages of manufacturing system design. This paper is mainly concerned with selecting the most appropriate conveyor for handling ceramic tiles during it production phases. The handling process in this application is characterized by dealing with fragile product as well as exposure to high temperature. Generally, such a decision inherently entails several conflicting qualitative and quantitative criteria. Accordingly, a multi-criteria decision making model has been developed using the Analytic Hierarchy Process (AHP) to assist the system designer in selecting the most appropriate conveyor. In this study, four conveyor alternatives have been considered. The results of the model implementation recommended slat conveyors as the best alternative for serving in the ceramic tile manufacturing environment, followed by belt and chain conveyors, while the last one in the ranking is the roller conveyor. Besides, the developed model can be used to perform sensitivity analysis to explore how the decision could be affected in response to changes in the decision maker's preferences related to the considered criteria.
\end{abstract}

Keywords: Analytic Hierarchy Process, Conveyors, Material Handling Equipment Selection

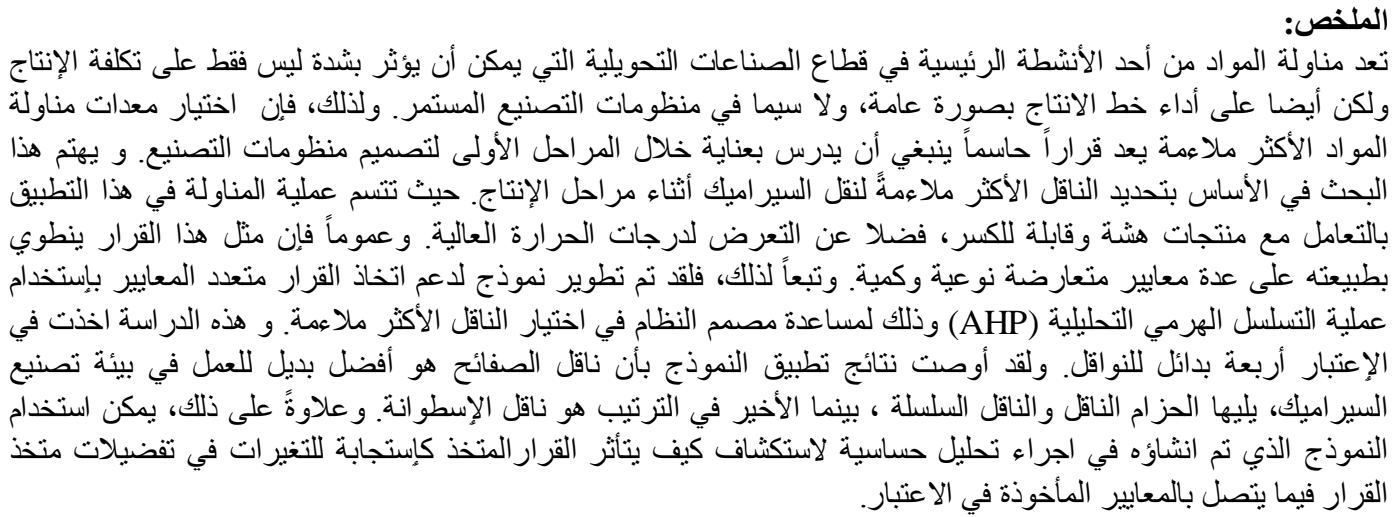




\section{INTRODUCTION}

In most of the manufacturing operations, material handling constitutes a significant ratio of the production cost. Besides, the performance of the material handling equipment directly affects the performance of the entire production line, particularly in continuous and transfer manufacturing systems. Accordingly, selecting the appropriate material handling equipment can be considered as one of the critical decisions in manufacturing system design. Nevertheless, the selection process of the suitable handling method is not always straight forward, as it incorporates several conflicting criteria. Sometimes it can be a challenging task, particularly in the presence of some constraints and conditions such as handling fragile materials associated with complicated handling factors like high temperatures and heavy weights. Hence, selecting the suitable handling equipment can be modeled as multi-criteria of decision making that should be properly considered in the early stages of manufacturing system design. Multi-criteria decision making methods have employed by several researchers to support the decisions related to the selection of material handling equipment in different applications [1-12]

Several types of material handling equipment are discussed in [13] as; moving carts and trucks, elevators, conveyors. The usage of moving carts and trucks in addition to small vehicles needs a wide working area for maneuvering. Likewise, elevators can be widely used for raising the materials from a certain level in the production line to another level. On the other hand, conveyors can be flexibly used with different applications via continuous and transfer production lines. Generally, conveyor systems can be used to facilitate the handling materials process, especially with heavy and hot materials. Types of belt, roller, chain and slat conveyors are commonly used in the continuous and transfer manufacturing lines such as ceramic production line.

The belt conveyor consists of a strong flexible belt in addition to two pulleys, one of these pulleys is used to drive the belt by a suitable motor. Moreover, the flexible belt must have high strength in addition to sufficient flexibility properties, especially with using a thin pulley [14]. Belt conveyors have many advantages as; simple design, safe, light weight, low fixed and maintenance costs, low power consumption, fast repairing, ease of maintenance and it has suitable ability to be reconfigured. On the other hand, belt conveyors have some disadvantages as; high breakdown frequency, moderate durability, Low working flexibility with different sizes and temperatures.

The roller conveyor is a series of cylindrical rollers fixed with a suitable frame on vertical stands. The rolling motion of these cylinders facilitates the handled product motion from one working station to the next one [15]. Furthermore, roller conveyors have many advantages as; safe, moderate fixed cost, low maintenance cost, acceptable power consumption, fast repairing, good durability, flexibility for working with different temperatures in addition to ease of maintenance. Conversely, this conveyor also has some disadvantages as; high conveying risk especially in the presence of fragile products, low flexibility for working with different sizes in addition to the difficulties of fitting in place and low reconfigurability.

The chain conveyor has two I-beam parallel lines tracks to facilitate the sliding motion of suitable cross carriers. These cross carries can easily slide between these parallel lines to convey the products[16, 17]. Moreover, chain conveyors have many advantages as; moderate fixed cost, low maintenance cost, low power consumption, good durability, and flexibility for working with different temperatures. On the other hand, this conveyor also has disadvantages as; high conveying risk with fragile products, low flexibility for working with different sizes in addition to the difficulties of fitting in place and low reconfigurability.

The slat conveyor consists of sprockets, chains, metal plates connected to each other with suitable hinges in order to form a heavy slated belt [18]. Slat conveyors have many advantages as; low breakdown frequency, high durability, high working flexibility with different sizes and temperatures. On the other hand, slat conveyor has some disadvantages such as complicated design, heavy weight, high fixed cost, high maintenance costs, high power consumption, long repairing time, and maintenance difficulties.

This paper is concerned with applying multi-criteria decision making to support selecting the most suitable conveyor in ceramic tiles production lines considering different conveying requirements such as surrounding high temperature in frying and glazing stages. The belt conveyors usage for conveying manufactured tiles in ceramic production line are discussed in many published scientific papers as [7, 19-21]. Moreover, the roller conveyors can be used for conveying materials in production lines with some design limitations and precautions related to conveying fragile materials like ceramics $[22,23]$. Also, the chain conveyor can be widely used for conveying ceramic tiles through frying and glazing stages [22, 23]. Furthermore, the slat conveyor can safely convey the ceramic tiles [24].

The remainder of this paper is structured as follows: Section 2 explains the AHP methodology to be utilized for model building. Section 3 represents the details of building the multi-criteria decision model using Analytic Hierarchy Process (AHP). Section 4 is allocated to the results and discussion. Finally, Section 5 is devoted to the conclusion.

\section{METHODOLOGY}

AHP has been extensively employed for modeling multi-criteria decision problems in diverse domains. This can be attributed to its simplicity and effectiveness in incorporating quantitative as well as qualitative criteria in 
the overall assessment. Besides, AHP can be systematically applied in complex decision scenarios through the hierarchical decomposition of the goal into criteria and subcriteria. In the AHP structure, the decision alternatives constitute the lowest level in the hierarchy. Accordingly, pairwise comparisons can be accomplished in order to obtain relative importance or weight of the lower layer elements with respect to each element in the immediate upper layer in the hierarchy. Commonly, these comparisons can be performed either by the decision maker or a group of experts can be consulted for this purpose. In addition, while performing the pairwise comparisons the assessment can be made not only using the available data, but human judgment can be used as well.

In AHP model, in order to construct a pairwise comparison matrix $A$ for $n$ criteria, the decision maker has to start with a square matrix $n \times n$. When comparing two criteria or alternatives with respect to any criterion in a higher level, the preference will be assigned based on Satty's numerical relational scale. [25]. The Satty's scale ranges from one to nine to indicate the intensity of importance, with 1 refers to equal importance, 3 refers to moderate importance, 5 refers to strong importance, 7 refers to very strong importance, and 9 refers to extreme importance. Besides, 2, 4, 6, and 8 are intermediate values between the two adjacent judgments. The entries in such a pairwise comparison matrix are represented by $a_{i j}>0$, where;

$a_{i j}= \begin{cases}1, & i=j \\ 1 / a_{i j}, & i \neq j\end{cases}$

Pairwise comparison matrices are reciprocal matrices. Therefore, the number of comparisons or judgments needed for each matrix with $n$ criteria is $n(n-$ 1)/2. After creating a pairwise comparison matrix, it has to be checked for inconsistency. The inconsistency can be assessed as recommended in [26]. It has been also recommended that the inconsistency ratio should not exceed 0.10. If it is more, the comparison matrix is considered inconsistent and judgments should be reviewed and improved. After performing all the required pairwise comparisons and checking their consistencies, the relative weights (local priorities) of the items of each level in the hierarchy with respect to an item in the next higher level are computed. One of the methods is to compute these weights as the components of the normalized eigenvector associated with the largest eigenvalue of their comparison matrix.

The vector of the weights $W$ may be determined by using the eigenvalue formulation as follows:

$$
A W=\lambda_{\max } \mathrm{W},
$$

where, $\lambda_{\max }$ is the principal eigenvalue of matrix $A$. For more details about the computations in the AHP, one may refer to Ref. [26]. Accordingly, the composite weight or the overall priority of each decision alternatives can be determined by aggregating the weights all over the hierarchy. The overall priority for each alternative is the weighted average of all priorities, which is the sum of the priority of this alternative with respect to each criterion multiplied by the weight of the corresponding criterion. The outcome of this synthesis is the overall ranking or overall priority of all the considered alternatives.

\section{CONVEYOR SELECTION MODEL DEVELOPMENT}

In this section, an AHP model will be developed to support the decision making in selecting the most appropriate conveyor to perform the planned task. Besides, a ranking for all the considered conveyor alternatives will be realized according to the considered decision making criteria. The model development entails several steps that will be explained in the remaining of this section.

In the context of tile conveying during ceramic manufacturing, the decision concerned with selecting the most appropriate conveyor can be hieratically structured as illustrated in Fig. 1. The decision hierarchy is composed of seven main criteria that have been proposed for assessing the different conveyor alternatives. Specifically, these main criteria include cost, durability, reliability, flexibility to fit in place, versatility, risk on product, and reconfigurability. In this model, the cost criterion is decomposed into three subcriteria. The first one is the initial cost of the conveyor which entails the purchase and installation cost of the conveyor. While, the second one is concerned with the power consumption associated with the conveyor operation. However, the third one represents the conveyor maintenance cost. Moreover, durability as one of the main criteria in the model refers to the useful expected service life, as defined in Ref. [27], for the conveyor. On the other hand, the reliability of the conveyor is decomposed into two subcriteria, namely, the failure rate and the repair or fixing speed. These measures are utilized in the assessment to reflect the most common reliability indices, namely, the mean time between failures (MTBF) and the mean time to repair (MTTR) [28].

Besides, the main criterion named flexibility to fit in place is used to assess how the conveyor route can be designed to fit different shapes to help in utilizing the available space in the workplace. Whereas, the main criterion versatility is further decomposed into sizes range and temperature range to reflect the conveyor's flexibility in handling ceramic tiles of different sizes and it is flexibility to serve in high temperature. The risk on product criterion refers to the expected bad effects, such as cracks or damage, on the product resulted during transfer via the conveyor. Finally, the reconfigurability criterion reflects the possibility that the conveyor can be reconfigured in the future to meet changed conveying needs.

In the field of ceramic tile manufacturing, four types of conveyors are commonly used. These are slat conveyor, belt conveyor, roller conveyor, as well as chain conveyor. These conveyor alternatives constitute the lower layer of the model and each one of them should be 
connected to all the elements immediately above it. The lowest level criteria or subcriteria directly connected to the alternatives are called the covering criteria.

In this model, eleven $(4 \times 4)$ pairwise comparison matrices should be constructed in order to evaluate each conveyor alternative with respect to each of the eleven covering criteria. Besides, three comparison matrices for the (cost, reliability, and versatility) will be constructed. These are to evaluate the decision maker's relative importance of the subcriteria connected to each of the mentioned main criteria. Therefore, for the cost criterion the pairwise comparison matrix, its dimensions will be $(3 \times 3)$. However, for reliability and versatility, it will be $(2 \times 2)$. Additionally, there is one matrix for assessing the relative importance of the seven main criteria with respect to the goal, which will be a $(7 \times 7)$ matrix. It should be pointed, discussions with experienced engineers and academic staff have conducted to help in making the judgments while developing these matrices

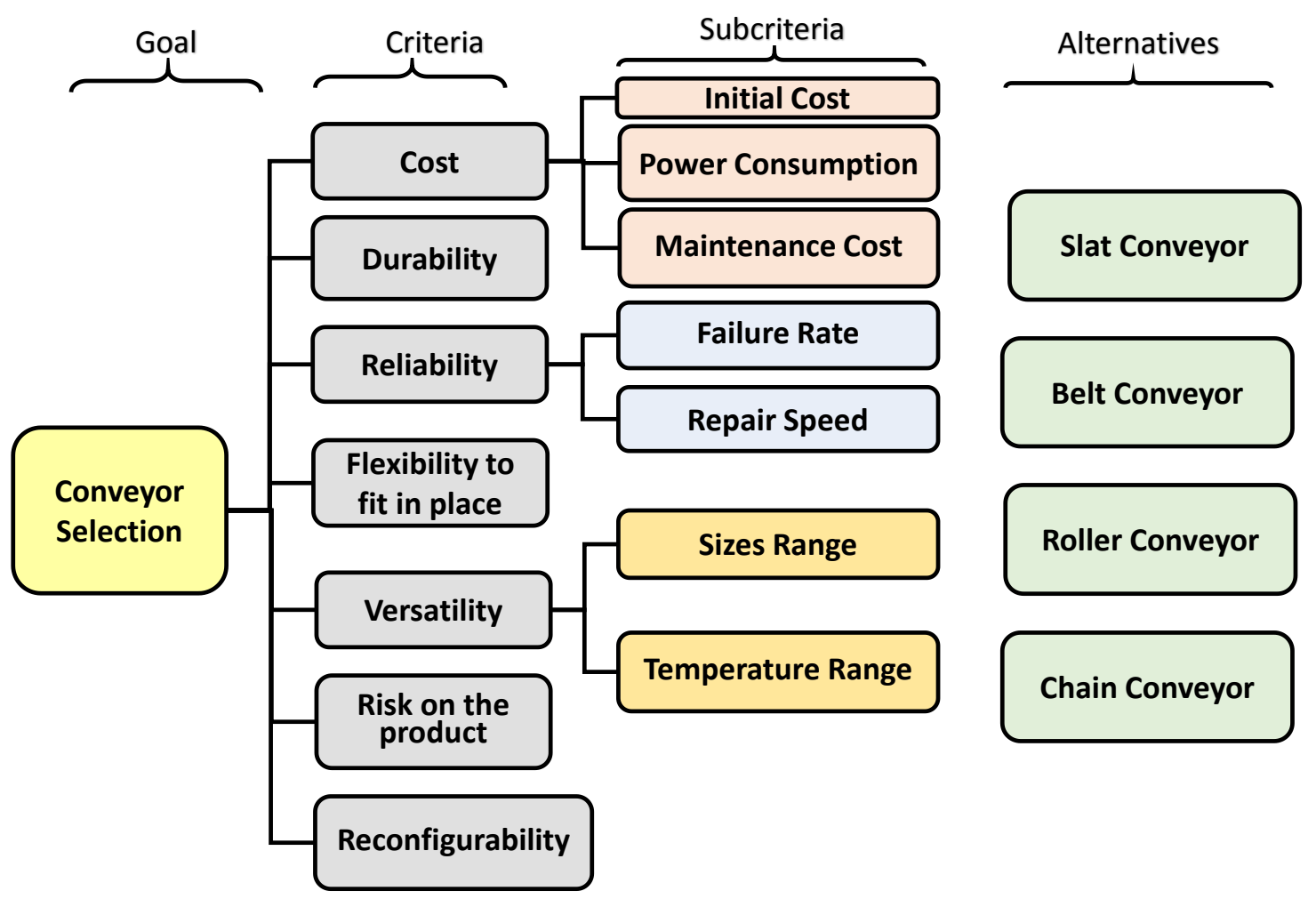

Fig. 1 Hierarchical structure of conveyor selection AHP model

\section{RESULTS AND DISCUSSION}

In order to construct the required matrices and perform the required calculations for the AHP implementation, the Super Decisions Software [29] has been employed. The pairwise comparison matrix that assesses the relative importance of the main criteria affecting the conveyor selection is illustrated in Table 1. Besides, the calculated priorities of these criteria are highlighted in the last column of the same table. Generally, the decision maker's preferences may vary according to the manufacturing environment and the organization's competitive strategy. The values in Table 1 reveal that the reliability has the dominant weight followed by the cost. This can be considered as an appropriate assessment because of the nature of the ceramic tiles manufacturing. In which, malfunctions in the conveyors will significantly affect the production of the entire line. Besides, the cost of production is very critical in this industry. Furthermore, the pairwise matrix for the cost subcriteria and their calculated priorities are shown in Table 2. Noticeably, the power consumption has the highest priority as it directly affects the variable cost of the production. In this application, the considered production is characterized by its high volume and this gives a higher priority to the variable cost as opposed to the fixed cost represented in this model in terms of the initial cost of the conveyor.

Likewise, the pairwise comparison matrices for the reliability and versatility subcriteria are presented in Table 3 and Table 4, respectively. In assigning these preferences it has been considered that the frequency of conveyor breakdowns is much more critical than the speed of repair as it results in interruptions in the production. Particularly, in ceramic tile manufacturing, the capability of the 
conveyor to withstand high temperature is much more important that handling different sizes.

For assessing the four considered conveyor alternative with respect each of covering criteria or subcriteria, eleven matrices

have been constructed. Samples of these are illustrated in

Table 5 and Table 6 for the power consumption and failure rate, respectively. The local ratings for each of the conveyor alternatives with respect to the considered criteria are highlighted in the last column in each table. Additionally, all the local ratings of the alternatives with respect to all the covering criteria is summarized in Table 7.

The final step is to perform model synthesis in order to obtain the overall ranking of the alternatives. The outcomes of model synthesis are presented in Fig. 2. The results provide an overall ranking for the four conveyor alternatives considered in the decision making process. According to the preferences of the different criteria specified in the model, the results reveal the slat conveyor is the best alternative, followed by the belt conveyor and the chain conveyor, while the last one in the ranking is the roller conveyor.

In different manufacturing circumstances, the preferences of the decision maker with respect to the considered criteria may vary. For instance, in a situation in which cracks or defects on some items cannot be tolerated or it would be very costly to scrap or downgrade those items, the decision maker would increase the weight of the risk on product criteria. To indicate such a scenario, sensitivity analysis can help in assessing the impact of increasing the risk on product weight on the overall ranking of the alternatives, as demonstrated in Fig. 3. This figure indicates that increasing the weight of risk on product criteria resulted in changing the decision and selecting the belt conveyor as the best alternative in this scenario. Consequently, the decision maker can perform sensitivity analysis as need so that the model can cope with the decision making environment.

Table 1 Pairwise comparison matrix of the main criteria with respect to the goal

\begin{tabular}{|ccccccccc|c|}
\hline $\begin{array}{c}\text { Inconsistency } \\
=0.0181\end{array}$ & Cost & Reliability & Durability & $\begin{array}{c}\text { Fit in } \\
\text { place }\end{array}$ & Versatility & $\begin{array}{c}\text { Risk on } \\
\text { Product }\end{array}$ & $\begin{array}{c}\text { Reconfigur- } \\
\text { ability }\end{array}$ & Priorities \\
\hline Cost & 1 & $1 / 2$ & 3 & 5 & 4 & 3 & 6 & $\mathbf{0 . 2 3 2}$ \\
\hline Reliability & 2 & 1 & 6 & 9 & 8 & 6 & 9 & $\mathbf{0 . 4 4 5}$ \\
\hline Durability & $1 / 3$ & $1 / 6$ & 1 & 3 & 2 & 1 & 4 & $\mathbf{0 . 1 0 0}$ \\
\hline Fit in place & $1 / 5$ & $1 / 9$ & $1 / 3$ & 1 & $1 / 2$ & $1 / 2$ & 2 & $\mathbf{0 . 0 4 3}$ \\
\hline Versatility & $1 / 4$ & $1 / 8$ & $1 / 2$ & 2 & 1 & $1 / 2$ & 2 & $\mathbf{0 . 0 5 8}$ \\
\hline Risk on Product & $1 / 3$ & $1 / 6$ & 1 & 2 & 2 & 1 & 3 & $\mathbf{0 . 0 8 9}$ \\
\hline Reconfigurability & $1 / 6$ & $1 / 9$ & $1 / 4$ & $1 / 2$ & $1 / 2$ & $1 / 3$ & 1 & $\mathbf{0 . 0 3 2}$ \\
\hline
\end{tabular}

Table 2 Pairwise comparison matrix of the cost subcriteria

\begin{tabular}{|c|c|c|c|c|}
\hline $\begin{array}{l}\text { Inconsistency } \\
\quad=0.0035\end{array}$ & 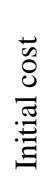 & 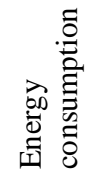 & 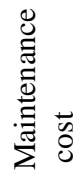 & 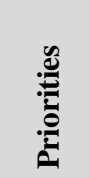 \\
\hline Initial cost & 1 & $1 / 5$ & $1 / 3$ & 0.109 \\
\hline Energy consumption & 5 & 1 & 2 & 0.582 \\
\hline Maintenance cost & 3 & $1 / 2$ & 1 & 0.309 \\
\hline
\end{tabular}

Table 3 Pairwise comparison of the reliability subcriteria

\begin{tabular}{|ccc|c|}
\hline Inconsistency $=0$ & $\begin{array}{c}\text { Failure } \\
\text { rate }\end{array}$ & $\begin{array}{c}\text { Repair } \\
\text { Speed }\end{array}$ & Priorities \\
\hline Failure rate & 1 & 3 & $\mathbf{0 . 7 5}$ \\
\hline Repair Speed & $1 / 3$ & 1 & $\mathbf{0 . 2 5}$ \\
\hline
\end{tabular}

Table 4 Pairwise comparison of the versatility subcriteria

\begin{tabular}{|ccc|c|}
\hline Inconsistency = 0 & $\begin{array}{c}\text { Sizes } \\
\text { range }\end{array}$ & $\begin{array}{c}\text { Temp. } \\
\text { range }\end{array}$ & Priorities \\
\hline Sizes range & 1 & 0.25 & $\mathbf{0 . 2}$ \\
\hline $\begin{array}{c}\text { Temperature } \\
\text { range }\end{array}$ & 4 & 1 & $\mathbf{0 . 8}$ \\
\hline
\end{tabular}

Table 5 Pairwise comparisons of the alternatives with respect to power consumption

\begin{tabular}{|c|c|c|c|c|c|}
\hline $\begin{array}{l}\text { Inconsistency } \\
\quad=0.0089\end{array}$ & 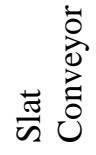 & 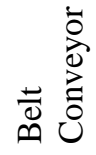 & 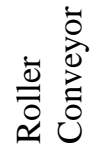 & : & శ్ర్ల \\
\hline Slat & 1 & $1 / 9$ & $1 / 7$ & $1 / 4$ & 0.046 \\
\hline Belt & 9 & 1 & 2 & 3 & 0.494 \\
\hline Roller & 7 & $1 / 2$ & 1 & 2 & 0.296 \\
\hline Chain & 4 & $1 / 3$ & $1 / 2$ & 1 & 0.164 \\
\hline
\end{tabular}

Table 6 Pairwise comparisons of the alternatives with respect to failure rate

\begin{tabular}{|c|c|c|c|c|c|}
\hline $\begin{array}{l}\text { Inconsistency } \\
\quad=0.0127\end{array}$ & 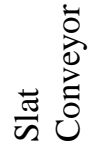 & 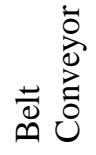 & 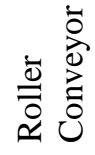 & : & 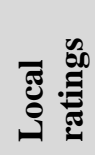 \\
\hline Slat & 1 & 9 & 5 & 2 & 0.535 \\
\hline Belt & $1 / 9$ & 1 & $1 / 3$ & $1 / 6$ & 0.049 \\
\hline Roller & $1 / 5$ & 3 & 1 & $1 / 3$ & 0.117 \\
\hline Chain & $1 / 2$ & 6 & 3 & 1 & 0.300 \\
\hline
\end{tabular}


Omayma A. Nada "A MULTI-CRITERIA DECISION MAKING MODEL FOR CERAMIC..."

Table 7 Summary of the local ratings of the alternatives with respect to the different covering criteria

\begin{tabular}{|c|c|c|c|c|}
\hline Alternati $\begin{array}{c}\text { Covering } \\
\text { Criterion }\end{array}$ & 离 $\frac{\bar{d}}{\grave{d}}$ & 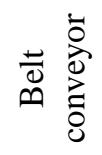 & 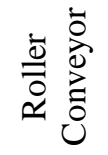 & 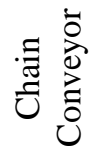 \\
\hline Initial cost & 0.051 & 0.510 & 0.236 & 0.202 \\
\hline Power consumption & 0.046 & 0.494 & 0.296 & 0.164 \\
\hline Maintenance cost & 0.041 & 0.455 & 0.252 & 0.252 \\
\hline Durability & 0.494 & 0.046 & 0.164 & 0.296 \\
\hline Failure rate & 0.535 & 0.049 & 0.117 & 0.300 \\
\hline Repair speed & 0.060 & 0.598 & 0.117 & 0.224 \\
\hline Fit in place & 0.314 & 0.091 & 0.052 & 0.543 \\
\hline Sizes range & 0.587 & 0.217 & 0.067 & 0.129 \\
\hline Temperature range & 0.321 & 0.036 & 0.321 & 0.321 \\
\hline Risk on product & 0.101 & 0.679 & 0.066 & 0.154 \\
\hline Reconfigurability & 0.053 & 0.321 & 0.097 & 0.530 \\
\hline
\end{tabular}

\section{CONCLUSION}

Selecting the appropriate material handling equipment in manufacturing systems is a critical decision, as it can significantly affect the system performance. More specifically, this paper considered the problem of conveyor selection in the production of ceramic tiles. Generally, the conveyor selection problem inherently entails several conflicting qualitative and quantitative criteria. Accordingly, a multi-criteria decision making model has been developed using AHP to assist the system designer in selecting the most appropriate conveyor. In ceramic tile manufacturing, four conveyor alternatives are considered to be the most widely employed conveyors in this industry. These include slat conveyors, belt conveyors, roller conveyors, as well as chain conveyors. Typically, each type of these conveyors has its advantages and disadvantages. Therefore, the developed model considers several criteria to assess each of these conveyors. Moreover, it integrates all the considered assessment criteria to obtain an overall rank for each of the considered alternatives. The results of the developed model recommended the slat conveyor as the best alternative, followed by the belt conveyor and the chain conveyor, while the last one in the ranking is the roller conveyor. Besides, sensitivity analysis can be conducted to assess the effect of changing the decision maker' $s$ preferences with respect to different criteria on the selection decision.

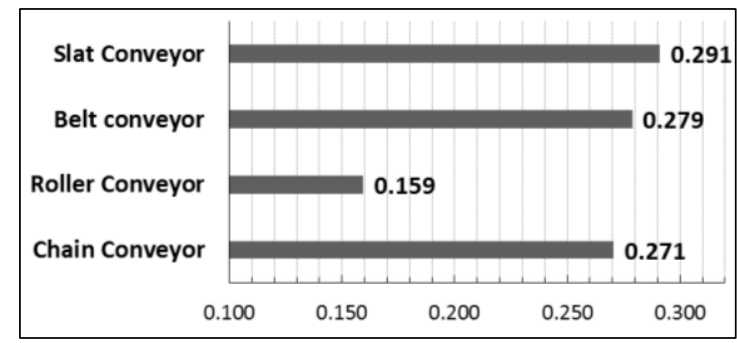

Fig. 2 Conveyor Alternatives Overall Ranking

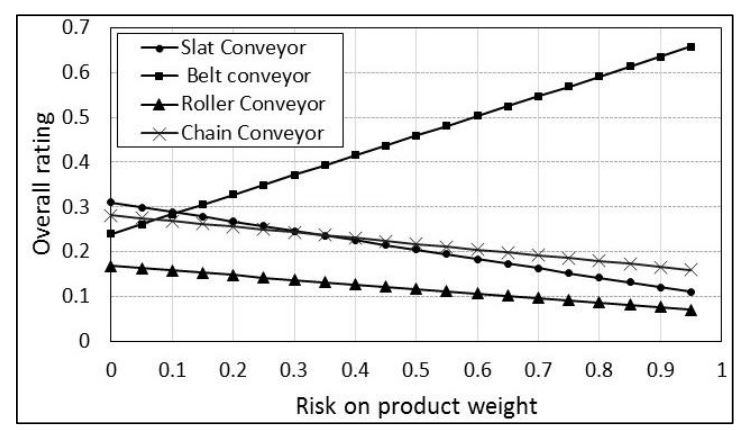

Fig. 3 Sensitivity analysis for the effect of risk on product

\section{REFERENCES}

[1] A. Ahmed and S. S. Lam, "Material Handling Equipment Selection Using Multi-attribute Utility Theory and Monte Carlo Simulation," in IIE Annual Conference. Proceedings, 2014, p. 3231.

[2] G. Anand, R. Kodali, and B. Santosh Kumar, "Development of analytic network process for the selection of material handling systems in the design of flexible manufacturing systems (FMS)," Journal of Advances in Management Research, vol. 8, pp. 123147, 2011.

[3] M. Andrejiová, Z. Kimáková, and D. Marasova, "Using AHP method at the determination of the optimal selection criteria of conveyor belts," Annals of the Faculty of Engineering HunedoaraInternational Journal of Engineering, vol. 11, 2013.

[4] F. Chan, "Design of material handling equipment selection system: an integration of expert system with analytic hierarchy process approach," Integrated Manufacturing Systems, vol. 13, pp. 58-68, 2002.

[5] A. Hadi-Vencheh and A. Mohamadghasemi, "A new hybrid fuzzy multi-criteria decision making model for solving the material handling equipment selection problem," International Journal of Computer Integrated Manufacturing, vol. 28, pp. 534-550, 2015.

[6] P. Jiamruangjarus and T. Naenna, "An integrated multi-criteria decision-making methodology for conveyor system selection," Cogent Engineering, vol. 3, p. 1158515, 2016.

[7] S. Jovčić, P. Průša, and S. Nikolicic, "Evaluation criteria of the belt conveyor using the AHP method and selection of the right conveyor by Hurwitz 
method," Advances in Science and Technology Research Journal, vol. 12, 2018.

[8] D. Komljenovic and V. Kecojevic, "Multi-attribute selection method for materials handling equipment," International Journal of Industrial and Systems Engineering, vol. 4, pp. 151-173, 2009.

[9] O. Kulak, S. I. Satoglu, and M. B. Durmusoglu, "Multi-attribute material handling equipment selection using information axiom," in The Third International Conference on Axiomatic Design, Seoul, Korea, 2004.

[10] S. Kumar and T. Raj, "Selection of material handling equipment for flexible manufacturing system using FAHP," Int. Jr. Recent Adv. Mech. Eng.(IJMECH), vol. 5, 2016.

[11] M. Mathew and S. Sahu, "Comparison of new multicriteria decision making methods for material handling equipment selection," Management Science Letters, vol. 8, pp. 139-150, 2018.

[12] H.-T. Nguyen, S. Z. M. Dawal, Y. Nukman, A. P. Rifai, and H. Aoyama, "An integrated MCDM model for conveyor equipment evaluation and selection in an FMC based on a fuzzy AHP and fuzzy ARAS in the presence of vagueness," PloS one, vol. 11, p. e0153222, 2016.

[13] M. P. Stephens and F. E. Meyers, Manufacturing facilities design and material handling: Purdue University Press, 2013.

[14] I. Daniyan, A. Adeodu, and O. Dada, "Design of a Material Handling Equipment: Belt Conveyor System for Crushed Limestone Using 3 roll Idlers," Journal of Advancement in Engineering and Technology, vol. 1, pp. 1-7, 2014.

[15]H. M. Amol Shenkar1, "Design Aspect of Roller Conveyor System," IJARIIE, vol. 4, no. 4, pp. 559561, 2018.

[16] C.-H. Lan, "The design of a multi-conveyor system for profit maximization," International Journal Advanced Manufacturing Technolgy, vol. 22, pp. 510 $-521,2003$.

[17]M. M. F .I .Malek, S. Rubiah, M.N. Mansor, M.A.Muda "Design And Development to Improve Mechanism of Conveyer System Part 1," in 2nd Integrated Design Project Conference (IDPC) 2015, Faculty of Mechanical Engineering, Universiti Malaysia Pahang, 11 Dec 2015.

[18] U. A. P. Abhijeet K. Baji, Prof. Dr. V. R. Naik, "Design and Modeling of Slat conveyor for Two Wheeler Assembly line," International Research Journal of Engineering and Technology (IRJET), vol. vol. 5, no. 6, pp. 2843-2847, , 2018.

[19] A. Tunali and N. T. Selli, "Industrial Plant Application of Hydrophobic Coating on Tile Surface," Polymers and Polymer Composites, vol. 21, pp. 157-160, 2013.

[20]Z. Hocenski and T. Keser, "Failure detection and isolation in ceramic tile edges based on contour descriptor analysis," in 2007 Mediterranean Conference on Control \& Automation, 2007, pp. 1-6.
[21] C. Medina, S. d. Rojas, M. Frías, and A. Juan, "Using Ceramic Materials in Ecoefficient Concrete and Precast Concrete Products," in Advances in Ceramics - Electric and Magnetic Ceramics, Bioceramics, Ceramics and Environment, C. Sikalidis, Ed., ed. IntechOpen: , 2011.

[22] I. A. Levitskii, S. E. Baranceva, and A. I. Pozniak, "Researches in the field of producing ceramic tiles of lower material capacity for interior wall facing," Engineering Structures and Technologies, vol. 5, pp. 1-10, 2013.

[23]F. Silva, P. Arezes, and P. Swuste, "Risk management of occupational exposure to nanoparticles during a development project: A case study," Dyna, vol. 83, pp. 9-16, 2016.

[24] R. Casasola, J. M. Rincón, and M. Romero, "Glassceramic glazes for ceramic tiles: a review," Journal of Materials Science, vol. 47, pp. 553-582, 2012.

[25]T. L. Saaty, "Decision making with the analytic hierarchy process," International journal of services sciences, vol. 1, pp. 83-98, 2008.

[26] T. L. Saaty, Decision making for leaders: the analytic hierarchy process for decisions in a complex world: RWS publications, 1990.

[27]D. Garvin, "Competing on the eight dimensions of quality," Harv. Bus. Rev., pp. 101-109, 1987.

[28]D. Zhang, Y. Zhang, M. Yu, and Y. Chen, "Reliability evaluation and component importance measure for manufacturing systems based on failure losses," Journal of Intelligent Manufacturing, vol. 28, pp. 1859-1869, December 012017.

[29] Super Decisions Software, verson 2.8, Creative Decisions Foundation, Retrieved from, https://www.superdecisions.com/. (Accessed: 15, Feb., 2018). 